\title{
Understanding what asthma plans mean: a linguistic analysis of terminology used in published texts
}

\section{*Nicola Ring ${ }^{a}$, Hilary Pinnock ${ }^{b}$, Caroline Wilson ${ }^{a}$, Gaylor Hoskins ${ }^{c}$, Ruth Jepson ${ }^{a}$, Sally Wykea, Aziz Sheikh ${ }^{b}$}

\footnotetext{
a School of Nursing, Midwifery and Health, University of Stirling, Stirling, UK

${ }^{b}$ Allergy and Respiratory Research Group, Centre for Population Health Sciences, The University of Edinburgh, Edinburgh, UK

' Department of General Practice, University of Dundee, Tayside, UK
}

Original submitted 21st January 2010; resubmitted 26th May 2010; revised 5th November 2010; accepted 25th December 2010; online 28th March 2011

\begin{abstract}
Aim: To identify from the literature what terms are used for 'asthma plans', with what meaning, and in what context(s).

Methods: Linguistic analysis of a selected body of asthma literature from 1989-2009.

Results: A wide range of asthma plan terminology was evident, with terms such as 'action plans', 'self-management plans' and 'treatment plans' being applied inconsistently and synonymously. For individual patients the term 'asthma plan' can describe a clinically-determined list of prescribed medication, an agreed plan to guide self-management of changing symptoms, or a more holistic 'living with asthma' plan. In some contexts the term 'asthma plan' was also used to describe an organisational system of care, which causes further ambiguity. Conclusions: Within the literature, a plethora of terms is used inconsistently and with varied meaning. This is a potential, but previously unrecognised, barrier to asthma plan implementation. A taxonomy of asthma plans and a standardised definitions of terms is required.

(C) 2011 Primary Care Respiratory Society UK. All rights reserved.

N Ring et al. Prim Care Respir J 2011; 20(2): 170-177

doi: $10.4104 /$ pcrj.2011.00012
\end{abstract}

Keywords asthma, action plans, self-management plans, terminology, meaning, linguistic analysis

See linked editorial by Reddel on pg 116

The full version of this paper, with online appendices and additional references, is available online

at www.thepcrj.org

\section{Introduction}

'When I use a word,' Humpty Dumpty said ... 'it means just what I choose it to mean - neither more nor less.' 'The question is,' said Alice, 'whether you can make words mean so many different things.' 'The question is,' said Humpty Dumpty, 'which is to be master - that's all'.'

Asthma plans, first recommended 20 years $\mathrm{ago}^{2}$ in an attempt to reduce high levels of asthma morbidity and mortality, ${ }^{2-4}$ are regarded as good practice. ${ }^{5,6}$ Yet despite their clinical benefits, ${ }^{7}$ they continue to be under-promoted by health professionals and under-utilised by patients and/or carers for reasons that remain poorly understood. ${ }^{8-13}$

There are many definitions of asthma action plans. ${ }^{6,14}$ In this paper we have defined them as, 'a written or electronic record, agreed between a person with asthma (or their parent/carer) and their health professional(s), providing personalised guidance on what action they should take when their asthma symptoms and/or peak flow deteriorates'. ${ }^{15}$

In our previous systematic review of controlled trials that evaluated interventions incorporating asthma action plans, we noted potentially important inconsistencies in asthma action plan terminology. ${ }^{16}$ This observation was reinforced whilst conducting a qualitative synthesis of the evidence on what helps or hinders the promotion and use of asthma action plans. ${ }^{17}$ This insight suggested that confusion in terminology could be a

\footnotetext{
* Corresponding author: Ms Nicola Ring, School of Nursing, Midwifery and Health, University of Stirling, RG Bomont Building, Stirling, FK9 4LA, UK. Tel: +44 (0)1786 466351 E-mail: nicola.ring@stir.ac.uk
} 
significant, but previously over-looked, barrier to the promotion of such plans by health professionals and their use by patients.

To explore this issue further we undertook a detailed analysis of the relevant asthma literature. Our aims were to:

(i) Explore the extent of variation and inconsistencies in asthma plan terminology by identifying what terms are used in the literature, when, by whom, and with what meaning

(ii) Propose a taxonomy of asthma plan terms and definitions.

\section{Methods}

Our study was guided by the principles of Biber's model of linguistic analysis. ${ }^{18}$ This model (Box 1 ) is commonly used in a range of academic disciplines, but is unusual within healthcare. Its main strength is that it enables systematic consideration of a variety of issues including the meaning and frequency of asthma plan terms, as well as their development and use over time.

First, we identified a 'corpus' or body of texts ${ }^{18}$ as the basis for our linguistic analysis. Included texts had to provide insight into the introduction and development of asthma plans, specifically enabling us to identify and analyse definitions of asthma plans, the actual terms used, and their context(s) of use. We aimed to identify an extensive, but not exhaustive, range of professionally-focused literature.

We used several different sources to identify the corpus. Our systematic reviews of asthma action plan promotion and use provided us with a core body of literature ${ }^{16,17}$ (see Table 1). However, for the linguistic analysis our corpus needed to be

\section{Box 1: Biber et al's (1998) corpus-based lexico-graphic approach. ${ }^{18}$}

This approach uses the following questions to facilitate understanding of people's use of words.

1. What is the frequency of a word relative to other related words? This enables identification of common and uncommon words as well as how often certain words are used.

2. What words commonly co-occur with a particular word? This considers the distribution and grouping of words - their 'collocations'.

3. How are seemingly synonymous words used and distributed in different ways? This investigates the pattern, 'use and distribution of synonyms in a corpus'.

4. What are the meanings associated with a particular word(s)? This is used to 'identify the meaning of words by looking at their occurrences in natural contexts'.

5. What non-linguistic association patterns does a particular word have? This helps 'understand the association patterns between different words and non-linguistic factors' e.g. how words develop over time and/or are distributed differently.

6. How are senses and uses of a word distributed? This includes consideration of the 'different senses and grammatical functions of a word'.

\section{Table 1. Literature searching for the linguistic analysis.}

Step 1: Search for randomised controlled trials (RCTs) with interventions to encourage the promotion and use of individual asthma action plans:

MEDLINE, EMBASE, CINAHL, PsycINFO, ERIC, Cochrane Library, DaRE, SSCI and SCI were searched from 1960-2006 using a combination of medical subject headings (MeSH) and keywords. Key search terms were mapped to existing subject headings, and included asthma, respiratory disease, action plans, self-management plans and trials. This search was conducted in 2007 with 7,993 potential papers screened. (Full details of this systematic review have been reported elsewhere). ${ }^{16}$

Step 2: Search for qualitative studies reporting what helps or hinders individual asthma action plan promotion and use: CINAHL, MEDLINE, EBM Reviews, EMBASE, British Nursing Index, Social Sciences Citation Index, HEALTH and PsycINFO were searched from 1990-2009. Key topic search terms included: asthma, respiratory disease, action plans, self-management plans, self-care and self-management. This search was conducted in February-April 2009 with 1665 potential papers screened. (This systematic review and qualitative synthesis is also published in full elsewhere). ${ }^{17}$

\section{Step 3: Search for papers not using RCT or qualitative research methods:}

MEDLINE, British Nursing Index and the Cochrane Database of Systematic Reviews were searched from 1950-1995 to identify relevant texts including editorials, surveys, systematic reviews, discussion and review papers. Search terms included: asthma, respiratory disease, action plans, self-management plans, asthma management plans, treatment plans. The search was conducted March-April 2009 with 269 potential references screened.

Step 4: Following up of citation lists in seminal publications:

This included following up potential references in key texts, for example, early asthma guidelines. References were reviewed and followed up in March-May 2009. 
broader, extending beyond research studies to enable us to trace the concept of asthma plans from their historical roots. In March-April 2009 we therefore extended these earlier searches back to 1950 to find other key texts - especially guidelines, position statements and opinion papers - and thus overall our searches covered the time period 1950-2009 (Table 1). We also reviewed the reference lists of key texts on asthma plans for additional inclusions.

Building the corpus was an iterative process, which involved reading and re-reading a considerable number of potentially relevant texts retrieved through the various searches. Individual texts were considered for inclusion on a case-by-case basis with judgements being based on whether they provided new insights into the topic of asthma plan terminology. For example, documents were included if they were primary sources for specific asthma plan terms, if they introduced a new variant of a term, or they provided an international perspective. Where there was any uncertainty, the wider research team was consulted.

Second, to understand the use of asthma plan terms we applied the six principle questions of Biber's model to the corpus (Box 1). We initially identified the frequency of words, collocations and synonymous terms (questions 1-3, Box 1). ${ }^{18}$ This was achieved by extracting relevant asthma plan terms onto a specially developed grid (a summary of which is shown in Table 2, available online at www.thepcrj.org). Generally we started with the most recent items from the corpus, tracing terms backwards. This process allowed us to construct a terminology timeline (Tables 2-3, both available online at www.thepcrj.org), providing the historical and international context for the terms used as well as understanding the breadth and frequency of terms. From this initial starting point, we then deepened our analysis by addressing questions 4-6 (Box 1), including identification of the meaning of words and their usage, ${ }^{18}$ again extracting relevant data into our developing timeline and grid. Although we answered the six questions systematically, of necessity this process was iterative as new insight often meant we needed to re-examine terms and texts. Data extraction and analysis were undertaken manually by NR and checked for accuracy by the wider team. By working through Biber's principle questions, ${ }^{18}$ over-arching themes relating to the terminology emerged. These are reported below.

\section{Results}

The final corpus (body of literature) was adequately sized, ${ }^{19}$ comprising 84 key texts published between 1989 and 2009. Included texts could be categorised broadly as national and international guidelines or consensus statements $(n=18)$, research studies $(n=42)$, and other publications by prominent researchers referring to asthma action plans specifically or asthma management generally (for example, review papers) $(n=24)$.

\section{The terminology mire}

An early observation was the extent of variations and inconsistencies in the relevant terminology. Action plans and self-management plans were the most frequently occurring terms, with both appearing in the asthma literature from the 1980s. Variants of these terms such as self-management action plan were also in common usage (as illustrated in Table 2 online). Such variation had consequences for our analysis, in that whilst the initial focus was specifically on action plans in response to worsening asthma, it became clear that we needed to broaden the approach to consider terms used for plans in asthma care more generally.

\section{Historical considerations}

To aid understanding and interpretation of the texts we needed to find a path through this 'terminology mire'. Biber's model $^{18}$ enabled us to trace how asthma plan terminology had evolved over time: the timeline is summarised in Table 2 with some detailed examples in Table 3 (both tables available online at www.thepcrj.org).

Specific references to self-management plans or action plans first appeared in the asthma literature in 1989..$^{20,21}$ However, international differences in terminology were evident from the outset with early (1989-1990) Australian and New Zealand asthma guidelines referring to 'written action plans' and 'asthma management plans', 2,21 whilst UK guidelines advocated 'self-management plans'.22 By comparison, the term 'action plan' was not introduced into UK guidelines until 2003, a decade later. ${ }^{23}$

Mapping asthma publications onto this timeline demonstrated how soon after the introduction of such terms terminology was being applied interchangeably and/or inconsistently. We found many examples of inconsistent use of terms within and between documents over the last two decades (Box 2). As we analysed the actual terms used and the grouping of words ('collocations' ${ }^{\prime 18}$ ), the introduction of subtle but specific variations in asthma plan terminology were also apparent. The emergence of 'guided self-management

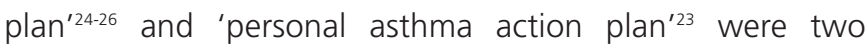
examples of this phenomenon. Tables 2 and 3 demonstrate that even where new terms were adopted or recommended, older terms continued to be used. This variation and inconsistency appeared confusing.

\section{Different types and levels of asthma plans}

Linguistic analysis of the terms used, their definitions and textual context, revealed that asthma plans can be differentiated by whether they are aimed at the individual (detailing actions that a patient/carer with asthma should take) or healthcare organisation (detailing an organisational strategy for supporting the delivery of asthma care). 


\section{Box 2: Illustrates the variety of asthma plans referred to, and their inconsistent use, in two key documents from the 1990s and 2000s.}

Example A: Global Initiative for Asthma (GINA) guidelines (2008). ${ }^{6}$

Within the text there are references to:

'personalised, written self management plan', 'personalised, written self management action plan', 'personal asthma action plan in response to worsening asthma', 'written action plan for regular medications and for worsening asthma', 'guided self management plan'.

Web references include:

'Self-management plans' and 'international asthma management plans'.

Illustrations:

One figure is labelled 'action plan to maintain asthma control' but the text referring to it cites 'asthma plan'.

Example B: National Heart, Lung \& Blood Institute guidelines (1992). ${ }^{24 ; 25}$

Within the text there are references to:

'treatment plans, medication plans for chronic management', 'plans for managing exacerbations', 'guided self-management plans', 'management plans' and 'colour-coded zone plans'.

Illustrations are labelled:

'asthma action plans' and 'asthma control plans' with reference to an 'emergency plan', 'medicine plan' and 'colour-coded zone plans'.

Plans aimed at the individual can be sub-divided into those that only provide patients with very basic information about their prescribed maintenance and reliever treatments, and more complex plans which aim to enable patients to recognise and respond to changes in peak flow measurements and/or symptoms by adjusting medications or seeking urgent professional treatment. Again, terminology was diverse, with these 'basic' and 'complex' individual asthma plans being variously called 'simple' or 'detailed', ${ }^{27}$ or 'incomplete' and 'complete', ${ }^{28}$ depending on their content and scope. Furthermore, in some cases, individual asthma plans sometimes extended beyond pharmacological treatment to consider more holistic asthma management information including lifestyle and health promotion.

Asthma plans can also operate at an organisational level. A well known example is the Australian Asthma Management Plan, in particular the six-step model or the $3+$ Visit Plan. ${ }^{21,29}$ These plans are still patient-focused in that they incorporate individual asthma plans, but they also encourage organisations (for example, general practices) to adopt a formal system of asthma care, including inviting patients for review and assessment. ${ }^{29,30}$

Within the corpus, we found many examples of authors clearly differentiating between the different types of asthma plans - individual (basic and complex) and organisational. 2,21,29-31 In contrast, there were many more instances where the meaning of asthma plans in relation to level and/or type was ambiguous. The terms 'management plan' and 'asthma management plan' were especially ambiguous as they can be used to mean asthma plans at individual and/or organisational levels. Based on our findings, we were able to differentiate between different types and levels of asthma plans and propose a taxonomy of terms for asthma plans (see Table 4).

\section{Fusion and seepage of terms}

As asthma care and self-management has developed over the last two decades, the volume of literature referring to asthma plans has increased - with the result that terminology has seeped and fused together, thus introducing further diversity into the texts we analysed.

Seepage relates to the synonymous use of different terms and was extremely common in the corpus. A consequence of seepage is that different terms become regarded as interchangeable; synonymous use of terms such as 'action plans', '(self)-management plans' or (self) 'treatment plans or

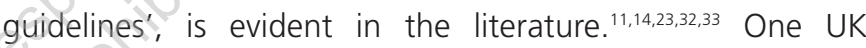
example of synonymous use is the 2003 asthma guideline, which recommended 'personal asthma action plans' as a 'replacement' for the earlier term 'self-management plans'. ${ }^{23}$ Asthma plans need to 'reflect the medical practice ... and health care system of [their] community.' ${ }^{\prime 34}$ For example, individual asthma plans can be implemented within an organisational asthma management plan and/or there can be differences in the costs and availability of medications which could affect their use. However, the healthcare context of different asthma plans was rarely explicitly stated in the literature we analysed, and this clearly has potentially important implications for the synonymous use of terms.

Fusion is where two or more terms come together to create a new term or meaning - for example, the 'selfmanagement plan system of care'.34,35 Defined in 2004 as a 'process whereby individual people with asthma make changes to their treatment in response to [recognised] changes in the severity of their asthma in accordance with pre-determined guidelines', ${ }^{34}$ this same definition was previously used simply to refer to 'asthma self-management' ${ }^{35}$ Analysis of this and other fused terms such as 'personalised, written self management action plan', ${ }^{6,36}$ within their textual contexts, suggests that fusion occurs as academics and health professionals endeavour to bring together and make sense of this complex picture in which different types of asthma plans, and different terms, are used nationally and internationally. Whilst the fusing of different terms is understandable, it may 
Table 4. Proposed taxonomy of terms for asthma plans.

\begin{tabular}{|c|c|c|}
\hline Term & Definition & Level of personalisation \\
\hline \multicolumn{3}{|c|}{ Individual asthma plans for those with asthma: } \\
\hline Asthma medication plan & $\begin{array}{l}\text { This is a basic plan which at its simplest will be a list of prescribed } \\
\text { medications. There is no expectation that the patient/carer will } \\
\text { adjust long-term therapy in response to varying asthma control. }\end{array}$ & $\begin{array}{l}\text { Provided by a health professional, after } \\
\text { discussion with patients/carers about the } \\
\text { medication prescribed. }\end{array}$ \\
\hline Asthma action plan & $\begin{array}{l}\text { This is a written or electronic plan for use by patients/carers when the } \\
\text { peak flow and/or symptoms change. This more complex plan contains } \\
\text { an asthma medication plan, but also enables patients/carers to recognise } \\
\text { deterioration and take action in accordance with pre-arranged } \\
\text { guidance. Patient/carer actions may include adjustment of medication } \\
\text { (e.g. using reliever inhalers, increasing inhaled corticosteroids or initiating } \\
\text { a course of oral corticosteroids) and advice on when and how to seek } \\
\text { professional advice. Patient/carer autonomy of actions should be } \\
\text { encouraged. Stepping down treatment when asthma control is achieved } \\
\text { may also be included in this plan. }\end{array}$ & $\begin{array}{l}\text { Ideally, an asthma action plan will be } \\
\text { developed, regularly reviewed and refined } \\
\text { by the health professional with the } \\
\text { patient/carer and be based on their joint } \\
\text { experience and knowledge of symptoms } \\
\text { and asthma management strategies. }\end{array}$ \\
\hline Living with asthma plan & $\begin{array}{l}\text { This holistic plan should include the components of an asthma medication } \\
\text { plan and asthma action plan, but extend beyond pharmacological } \\
\text { measures and response to changes in control to address the wider } \\
\text { issues of living with asthma. It could, for example, include general } \\
\text { lifestyle education and specific asthma information on avoiding triggers, } \\
\text { smoking cessation and the promotion of exercise. Arrangements for } \\
\text { on-going review and monitoring would be included. }\end{array}$ & $\begin{array}{l}\text { Personalisation is central to a Living with } \\
\text { asthma plan which is developed by the } \\
\text { patient/carer and professional working in } \\
\text { partnership. Ideally it would be based on } \\
\text { the patient's experience of their asthma } \\
\text { symptoms and their own management } \\
\text { strategies as well as on professional } \\
\text { expertise. }\end{array}$ \\
\hline \multicolumn{3}{|c|}{ Organisational asthma management systems: } \\
\hline $\begin{array}{l}\text { Asthma management } \\
\text { system }\end{array}$ & $\begin{array}{l}\text { This refers to organisational systems which describe a formalised } \\
\text { approach to ensure high quality care for people with asthma. } \\
\text { The onus of responsibility for delivering an asthma management system } \\
\text { will lie with the healthcare professional or healthcare organisation, though } \\
\text { this may be shared with the patient. An asthma management system may } \\
\text { embrace any aspect of delivery of care for people with asthma including } \\
\text { ensuring regular review or follow up after acute attacks, advice on } \\
\text { identification of poor control and appropriate management strategies. } \\
\text { A variety of asthma management systems exist worldwide, for example, } \\
\text { the Australian Asthma 3+ Visit Plan, }{ }^{30: 31} \text { the Finnish national asthma } \\
\text { programme }{ }^{62} \text { and the UK Quality Outcomes Framework asthma criteria. }{ }^{117}\end{array}$ & $\begin{array}{l}\text { Asthma management systems are likely } \\
\text { to be tailored to the context of the } \\
\text { organisation they are applied to e.g. } \\
\text { a particular country and/or general } \\
\text { practice. }\end{array}$ \\
\hline \multicolumn{3}{|c|}{$\begin{array}{l}\text { Notes on the proposed taxonomy: } \\
\text { 1. Although each plan has been defined and presented separately, in reality they will overlap (see Figure 1). } \\
\text { 2. Implicit acceptance by health professionals that patients (or parents/carers) should be involved in the joint development of asthma action } \\
\text { plans and Living with asthma plans, renders specific reference to 'self' in relation to such plans unnecessary. }\end{array}$} \\
\hline
\end{tabular}

be confusing especially since it is not always clear how new fused terms fit (if at all) with pre-existing ones.

The use of 'self' and personalisation of asthma plans

By considering the collocation of words, ${ }^{18}$ it appears that the prefix 'self' - as in 'self-management' plan, for example - may not be used simply to distinguish individual from organisational asthma plans, but that it may also have originally reflected a different philosophical approach to asthma care. Specifically, initial reports of the Australian and New Zealand six-step asthma management plan did not specify 'self', 2,21,29,37 whereas the UK asthma guidelines from that same period did. ${ }^{22}$ Whilst these countries all recommended improved assessment, education and response to worsening asthma, early descriptions of the Australian and New Zealand asthma management plan appeared primarily to emphasise a medically-led model of asthma management. ${ }^{38}$ This is supported by early references to this plan as a 'formalised structure', with patients having an 'asthma management plan developed by their doctors ${ }^{29}$ and being 'supervised' in their changes to treatment. ${ }^{2,21}$ By comparison, the UK asthma guidelines explicitly acknowledged greater patient participation, specifically referring to 'selfmanagement' with 'patients trained to manage their own treatment rather than be required to [first] consult their doctor'.22

Within the corpus, where texts made reference to 'self' 
(e.g. self-management plans), the extent or nature of patient participation in the process of developing that plan was rarely specified. 'Variation' in the preparation of written asthma plans $^{28}$ is acknowledged, but reporting of such variations tends to focus on differences in format and style of the plan rather than the degree of patient participation in their development. ${ }^{28,34,35}$ In practice, 'personalisation' of asthma plans may range from a generic plan which has a patient's name and prescription listed by a health professional, to one which has been developed through joint negotiation between professional and patient emphasising their complementary experience and expertise. Although asthma plans are commonly referred to in the asthma literature as 'individualised' or 'personalised', within the texts we analysed such words were used interchangeably and inconsistently and were rarely defined - so the extent of patient participation in asthma plan development was frequently unclear.

\section{Discussion}

Asthma plans were developed as a medical response to increasing asthma mortality and morbidity in the late 1980s/early 1990s and are now recommended internationally. ${ }^{6}$ Since their introduction, asthma care has gone through a period of great change - in particular, a greater emphasis on proactive management through (for example) the introduction of nurse-led asthma clinics. In the context of such changes in practice it is inevitable that the terminology applied to asthma plans has evolved, and with the recent use of alternative terms such as 'first aid asthma plans' ${ }^{\prime 39,40}$ it continues to do so.

Contemporaneously, the balance of care for long-term conditions generally has shifted towards increased patient selfmanagement. ${ }^{41-43}$ Asthma plans need to be seen in the context of increasing participation of people with long-term conditions in decision-making and managing their care in partnership with health professionals. ${ }^{41,42,44-46}$ However, this broader policy context has the potential for contributing further to the terminology mire - witness the recent introduction in England of personalised care plans (conceived as a holistic plan encompassing health and social well-being) for all those with long-term conditions, ${ }^{47}$ and health action plans for those with learning disabilities. ${ }^{48}$ Such developments potentially introduce yet more 'plans' for those patients with asthma and other longterm conditions as well as their health professionals.

Using Biber's approach, ${ }^{18}$ linguistic analysis of professionallyfocused asthma literature identified appreciable inconsistency and variation in the terms used for asthma plans. Our analysis highlights that within the body of literature studied, asthma plan terminology is ambiguous and potentially confusing. Ambiguity of asthma plan terms is, however, both a symptom and cause of the current terminology mire; as the terminology seeps and fuses together, authors often opt for broad all-encompassing terms
Figure 1. Illustration of the proposed taxonomy showing the potential relationship between the different types of asthma plans.

Asthma management system

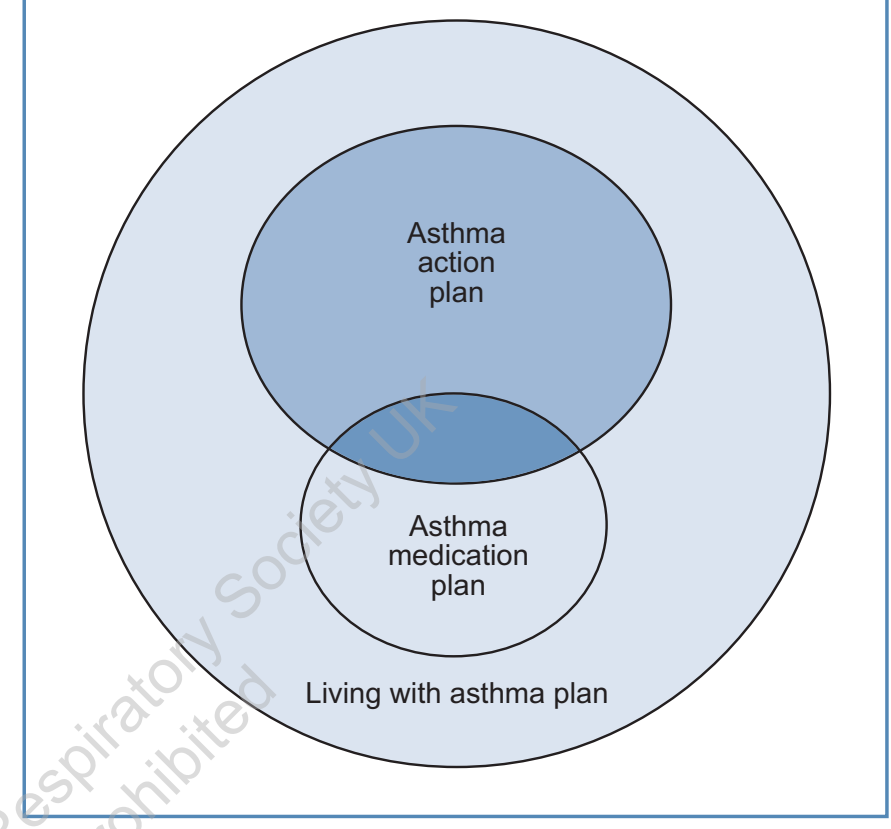

like 'asthma management plan', but such terms lack specificity, which ironically increases ambiguity.

This linguistic analysis highlights an urgent need to bring some clarity to this field. Based on our critique of the literature and related multi-disciplinary discussions, we have developed a taxonomy of the different individual and organisational asthma plans and standardised definitions (see Table 4 and Figure 1) which we hope will be debated by clinical and academic colleagues. Furthermore, we hope that colleagues will challenge, contribute to, and build on, this proposed framework so that we can subsequently arrive at an approach that brings more light than shade to this area of asthma care.

\section{Limitations and strengths}

This was an innovative research approach undertaken as part of a qualitative systematic review of what helps or hinders the promotion and use of individual plans by patients in response to worsening asthma (individual asthma action plans). ${ }^{17}$ Linguistic analysis may be supported by computer software, ${ }^{18}$ but this was not possible within the available resources. We have only been able to present a small selection of examples from the many texts we analysed to support our findings, but have endeavoured to present terminology from a variety of countries and sources to minimise the potential for bias. It is also possible that we have 'over-interpreted' some of the terms used by authors, perhaps reading more into the words used than was intended by the author(s). Also, although we used a 
variety of international sources within our analysis, we are a UK research team and this perspective may have influenced our analysis. Whilst we acknowledge such limitations, we believe our work nonetheless clearly demonstrates the extent of inconsistency surrounding asthma plan terminology within the literature and the need for clarification.

\section{Implications for practice and research}

Differences in the language used by patients and professionals when referring to asthma - for example, terms such as asthma attack and exacerbation - are recognised as a barrier to effective communication. ${ }^{49,50}$ Inconsistent asthma plan terminology may also contribute to poor communication, thus hampering the promotion and use of asthma plans in clinical practice as professionals and patients are exposed to a variety of different terms for diverse asthma plans with potential confusion about the type of plan they should be using and when. Further research is required to determine whether the ambiguous terminology found in the healthcare literature is reflected in confusion in clinical practice.

In trials, individual asthma plans are typically only one component of a complex intervention; a detailed description of the type and level of 'plan' as well as information about the context in which it was delivered is essential to enable its subsequent replication and implementation in practice or other trials. ${ }^{51}$ If factors such as the extent of patient participation in developing an asthma plan are not explicit, it makes comparison of different interventions through systematic review difficult ${ }^{16}$ and may partly explain differences in the reported effectiveness of individual asthma plans. .2-54. $^{5}$

Ambiguous use of terms has other implications for research. For example, those conducting interviews or surveys may be using different terms and meanings for asthma plans from their participants, with implications for the interpretation of their findings. For those conducting systematic reviews, inconsistent terminology brings additional challenges to the searching and screening of literature against inclusion criteria.

\section{Conclusions}

In this linguistic analysis we have sought to trace the conception and subsequent evolution over two decades of asthma plan terminology, and in so doing we have also traced the concept of asthma self-management. We have described the extent of inconsistency and terminology in the literature, and highlight the potential for creating confusion with implications for the delivery of clinical care as well as for the development of a robust evidence base. In order to address the need for clarification, we have proposed a taxonomy with standardised definitions which we hope will stimulate discussion and debate. Future developments will trigger further changes in terminology. Standardisation of terms is a foundation on which future change can build.

\section{Funding}

This work was funded by a grant from the Chief Scientist's Office of the Scottish Government as part of a larger systematic review. GH and HP are supported by Primary Care Research Career Awards also from the Chief Scientist's Office of the Scottish Government. SW is part-funded through a strategic research development grant jointly awarded by Scottish Funding Council, Chief Scientist's Office of the Scottish Government and NHS Education for Scotland.

\section{Acknowledgements}

John Paley, Senior Lecturer, Department of Nursing \& Midwifery, University of Stirling.

\section{Conflicts of interest}

HP chairs the Patient education and self-management Evidence Review Group of the British Thoracic Society / Scottish Intercollegiate Guideline Network asthma guideline. AS is a past chair of the British Thoracic Society's Science and Research Committee and a member of its Council and Executive. No other authors report any conflict of interests.

AS is Joint Editor-in-Chief of, and HP an Associate Editor of, the $P C R J$; neither were involved in the editorial review of, nor the decision to publish, this article.

\section{References}

1. Carroll L. Through the Looking Glass. London: Macmillan; 1871

2. Thoracic Society of Australia and New Zealand. Consensus on asthma: asthma management plan, 1989. NZ Med J 1989;103:16-8.

3. British Thoracic Association. Death from asthma in two regions of England. BMJ 1982;285:1251-5. http://dx.doi.org/10.1136/bmj.285.6350.1251

4. Rea $H$, Sears $M R$, Beaglehole $R$, et al. Lessons from the national asthma mortality study: circumstances surrounding death. NZ Med J 1987;100:10-3.

5. British Thoracic Society, Scottish Inter-collegiate Guideline Network. British Guideline on the Management of Asthma. Thorax 2008;63:iv1-iv121. http://dx.doi.org/10.1136/thx.2008.097741.

6. Global Initiative for Asthma (GINA). Global Strategy for Asthma Management and Prevention Report. www.ginasthma.org; 2008 (accessed 2008).

7. Gibson P, Powell H, Coughlan J, Wilson A, Abramson M, Haywood P, et al. Selfmanagement education and regular practitioner review for adults with asthma. Cochrane Database of Systematic Reviews 2002, Issue 3. Art. No.: CD001117. http://dx.doi.org/10.1002/14651858.CD001117.

8. Gibson P. Asthma action plans: use it or lose it. Prim Care Respir J 2004;13:1718. http://dx.doi.org/10.1016/j.pcrj.2003.12.001.

9. Gillies J, Sheikh A, Wiener-Ogilvie S, Huby G, Pinnock H, Partridge MR. Describing compliance with and identifying barriers and facilitators to the implementation of SIGN 63 (The British Guideline for the Management of Asthma) in a rural health board. (Report no. CZG/2/186). Edinburgh: Chief Scientist Office; 2006.

10. Hoskins G, McCowan C, Donnan P, Friend J, Osman L. Results of a national asthma campaign survey of primary care in Scotland. Int J Quality Health Care 2005;17:209-15. http://dx.doi.org/10.1093/intqhc/mzi036.

11. Sulaiman N, Barton C, Abramson M, et al. Factors associated with ownership and use of written asthma action plans in North-West Melbourne. Prim Care Respir J 2004;13:211-7. http://dx.doi.org/10.1016/j.pcrj.2004.04.002.

12. Tse $M$, Bauman $A$, Bridges-Webb $C$. Asthma management in general practice. Aust Fam Physician 1991;20:1085-92.

13. Wiener-Ogilvie S, Pinnock H, Huby G, Sheikh A, Partridge MR, Gillies J. Do practices comply with key recommendations of the British Asthma Guideline? If not, why not? Prim Care Respir J 2007;16:369-77. http://dx.doi.org/10.3132/pcrj.2007.00074.

14. National Heart Lung and Blood Institute (NHLBI) National Asthma Education and Prevention Program. Expert Panel Report 3: Guidelines for the diagnosis and management of asthma. Bethesda, USA: US Department of Health and Human Services, National Institutes of Health (NIH) \& NHLBI; 2007.

15. NHS Quality Improvement Scotland, Asthma UK (Scotland). Promoting the use 
of Personal Asthma Action Plans in Scotland: project specification strand two. Edinburgh: NHS QIS \& Asthma UK (Scotland); 2005

16. Ring N, Malcolm C, Wkye $S$, et al. Promoting the use of Personal Asthma Action Plans: a systematic review. Prim Care Respir J 2007;16:271-83. http://dx.doi.org/10.3132/pcrj.2007.00049.

17. Ring $N$, Jepson $R$, Wilson $C$, et al. Understanding what helps or hinders asthma action plan use: a systematic review and synthesis of the qualitative literature. Patient Educ Couns (2011) in press. http://dx.doi.org/10.1016/j.pec.2011.01.025

18. Biber D, Conrad S, Reppen R. Corpus Linguistics: investigating language, structure and use. Cambridge: Cambridge University Press; 1998.

19. Biber D. Methodological issues regarding corpus-based analyses of linguistic variation. Literary and Linguistic Computing 1990;5:257-69.

20. Beasley R, Cushley M, Holgate ST. A self management plan in the treatment of adult asthma. Thorax 1989;44:200-4. http://dx.doi.org/10.1136/thx.44.3.200.

21. Woolcock A, Rubinfeld A, Seale J, et al. Asthma management plan. Med J Aust 1989;151:650-3

22. British Thoracic Society, Research Unit of the Royal Colleges of Physicians of London, King's Fund Centre, National Asthma Campaign. Guidelines for management of asthma in adults: 1- chronic persistent asthma. BMJ 1990;301:651-3. http://dx.doi.org/10.1136/bmj.301.6753.651.

23. British Thoracic Society, Scottish Inter-collegiate Guideline Network. British guideline on the management of asthma. Edinburgh: BTS \& SIGN; 2003.

24. National Heart Lung and Blood Institute, National Institutes of Health. International consensus report on diagnosis and treatment of asthma. Eur Respir J 1992;5:601-41.

25. National Heart Lung and Blood Institute, National Institutes of Health. International consensus report on diagnosis and treatment of asthma. Clin Exp Allergy 1992;22:s1-s72.

26. Partridge MR. Patients self-assessment and treatment strategies for acute asthma. Res Clin Forums 1990;15:65-73.

27. National Asthma Campaign. Asthma who is in control? Review of evidence for the use of asthma self-management. London: National Asthma Campaign; 2001.

28. Gibson PG, Powell H. Written action plans for asthma: an evidence-based review of the key components. Thorax 2004;59:94-9. http://dx.doi.org/10.1136/thorax.2003.011858.

29. Philpott J, Ruffin R. New trends in asthma management. Aust Fam Physician 1991;20:1100-06.

30. Zwar N, Comino E, Hasan I, Harris M. General practitioner views on barriers and facilitators to implementation of the Asthma 3+ Visit Plan. Med J Aust 2005; 183:64-7.

31. Glasgow NJ, Ponsonby A-L, Yates R, Beilby J, Dugdale P. Proactive asthma care in childhood: general practice based randomised controlled trial. $B M J$ 2003;327:659-65. http://dx.doi.org/10.1136/bmj.327.7416.659.

32. Sheares BJ, Du Y, Vazquez TL, Mellins RB, Evans D. Use of written treatment plans for asthma by specialist physicians. Pediatr Pulmonol 2007;42:348-56. http://dx.doi.org/10.1002/ppul.20586

33. van der Palen J, Klein JJ, Zielhuis GA, van Herwaarden CLA, Seydel ER. Behavioural effect of self-treatment guidelines in a self-management program for adults with asthma. Patient Educ Couns 2001;43:161-9.

34. Holt S, Masoli M, Beasley R. The use of the self-management plan system of care in adult asthma. Prim Care Respir J 2004;13:19-27. http://dx.doi.org/10.1016/j.pcrj.2003.11.001.

35. Fishwick D, D'Souza WD, Beasley R. The asthma self-management plan system of care: what does it mean, how is it done, does it work, what models are available, what do patients want and who needs it? Patient Educ Couns 1997;32:s21-s33.

36. Price $D$, Wolfe S. Delivery of asthma care: patients' use of and views on healthcare services, as determined from a nationwide interview survey. Asthma J 2000;5:141-4.

37. Lane S, Smith S. The Paediatric Asthma Management Plan. The Queensland Nurse 1991;10:21.

38. Aroni R, Sawyer $S$, Abramson M, et al. Asthma self-management: what do we really mean? Aust J Prim Health 2003;9:10-17.

39. Asthma Foundation of Victoria. School Asthma Action Plan. Victoria, Australia: Asthma Foundation of Victoria; 2008.

40. Asthma UK (Scotland). In their own words: asthma services in Scotland from the perspective of children and young people. Edinburgh: Asthma UK (Scotland); 2008.

41. Long-term Conditions Alliance Scotland, Scottish Government. 'Gaun Yersel! The Self-Management Strategy for Long-Term Conditions in Scotland. Glasgow: Long-term Conditions Alliance Scotland \& The Scottish Government; 2008

42. Nolte E, McKee M. Caring for people with chronic conditions: a health system perspective. Maidenhead; Open University Press; 2008.

43. World Health Organization (WHO). Preparing a health care workforce for the 21st century: the challenge of chronic conditions. Geneva: WHO; 2005.

44. Department of Health. The Expert Patient: a new approach to chronic disease management for the 21st century. London: Department of Health; 2001.

45. Lorig KR, Sobel DS, Ritter PL, Laurent D, Hobbs M. Effect of a self-management program on patients with chronic disease. Eff Clin Prac 2001;4:256-62.

46. World Health Organization. General principles of good chronic care: integrated management of adolescent and adult illness. Geneva: World Health Organization; 2004.

47. Department of Health. Your health, your way: a guide to long-term conditions and self care - information for healthcare professionals. Leeds: Department of Health; 2009.

48. Department of Health. Health Action Plans: what are they? How do you get one? (a booklet for people with learning disabilities). London: Department of Health; 2002.

49. Aroni R, Goeman D, Stewart $K$, et al. Enhancing validity: what counts as an asthma attack? J Asthma 2004;41:723-31. http://dx.doi.org/10.108/JAS200027980

50. Vincent SD, Toelle BG, Aroni R, Jenkins CR, Reddel HK. 'Exasperations' of asthma: a qualitative study of patient language about worsening asthma. Med J Aust 2006;184:451-4.

51. Abraham C, Michie S. A taxonomy of behaviour change techniques used in interventions. Health Psych 2008;27:379-87. http://dx.doi.org/10.1037/02786133.27.3.379.

52. Bhogal SK, Zemek RL, Ducharme FM. Written action plans for asthma in children. Cochrane Database of Systematic Reviews; 2006. Art. No. CD005306. http://dx.doi.org/10.1002/14651858.CD005306.pub2.

53. Toelle BG, Ram FSF. Written individualised management plans for asthma in children and adults. Cochrane Database of Systematic Reviews; 2004. Art. No. CD002171. http://dx.doi.org/10.1002/14651858.CD002171.pub2.

54. Walters EH, Walters JAE, Wood-Baker R. Why have asthma action plans failed the consumer test? Med J Aust 2003;178:477-8.

\section{Available online at http://www.thepcrj.org}


Appendix.

Table 2. Some examples of differing asthma plan terminology used internationally and across different time periods.

\begin{tabular}{|c|c|c|c|c|}
\hline Term & $1980 \mathrm{~s}$ & $1990 \mathrm{~s}$ & $2000 \mathrm{~s}$ & Country ${ }^{\dagger}$ (examples only) \\
\hline (Asthma) ${ }^{\dagger+}$ action plans & $\checkmark$ & $\checkmark$ & $\checkmark$ & 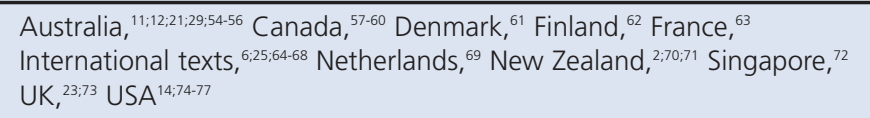 \\
\hline Asthma control plans & & $\checkmark$ & & International, ${ }^{24: 25}$ New Zealand ${ }^{35}$ \\
\hline (Asthma) management plans (generally) & $\checkmark$ & $\checkmark$ & $\checkmark$ & $\begin{array}{l}\text { Australia, }{ }^{11: 78} \text { International, }{ }^{24 ; 79} \text { Netherlands, }{ }^{80} \text { New Zealand, }{ }^{34: 81} \text { UK, }{ }^{20: 82 ; 83} \\
\text { USA }{ }^{32 ; 84-88}\end{array}$ \\
\hline $\begin{array}{l}\text { Asthma management plans (specifically the } \\
6 \text { step or } 3+\text { visit plan) }\end{array}$ & $\checkmark$ & $\checkmark$ & $\checkmark$ & Australia, 12;21:29;30;89 New Zealand ${ }^{2}$ \\
\hline (Asthma) medication plans & & $\checkmark$ & $\checkmark$ & International, ${ }^{24,25 ; 68: 79}$ USA $^{87 ; 90}$ \\
\hline First aid asthma plans & & & $\checkmark$ & Australia, ${ }^{39} \mathrm{UK}^{40}$ \\
\hline Guided self-management plan & & $\checkmark$ & $\checkmark$ & Finland, ${ }^{91}$ Germany, ${ }^{92}$ International, ${ }^{6: 24} \mathrm{UK}^{26: 93: 94}$ \\
\hline Negotiated (action) plan & & & $\checkmark$ & Australia, ${ }^{54} \mathrm{UK}^{95}$ \\
\hline Personalised (asthma) action plan & & & $\checkmark$ & Canada,${ }^{59}$ International, ${ }^{6} \mathrm{UK}^{5,23}$ \\
\hline $\begin{array}{l}\text { Personalised or individualised (asthma) } \\
\text { management plan }\end{array}$ & & $\checkmark$ & $\checkmark$ & International, ${ }^{53,79} \mathrm{UK}^{96}$ \\
\hline $\begin{array}{l}\text { Plans for managing exacerbations, dealing } \\
\text { with worsening asthma or for managing } \\
\text { asthma attacks }\end{array}$ & & $\checkmark$ & $\checkmark$ & Canada, ${ }^{97}$ International, ${ }^{24,25 ; 64 ; 68 ; 98}$ \\
\hline Self-action plan & & $\checkmark$ & $\checkmark 8$ & Canada, ${ }^{99 ; 100}$ France $^{63}$ \\
\hline Self-care plans for asthmatics & & $\checkmark$ & 8 & $U^{101}$ \\
\hline Self-management action plans & & 1 & $\checkmark$ & Canada, ${ }^{58}$ International, ${ }^{6}$ UK $^{36}$ \\
\hline Self-management plans & $\checkmark$ & $\checkmark$ & $\checkmark$ & $\begin{array}{l}\text { Canada, }{ }^{58 ; 60 ; 97 ; 99} \text { Finland }_{,}{ }^{62} \text { France }^{63} \text { International, }{ }^{6 ; 68} \text { New Zealand, }{ }^{34 ; 70 ; 71 ; 102} \\
\text { UK }^{20 ; 2 ; 36 ; 73 ; 93,101 ; 103-106} \text { USA }^{32 ; 107}\end{array}$ \\
\hline Self-management plan system of care & $\gamma$ & 8 & $\checkmark$ & New Zealand ${ }^{34: 35}$ \\
\hline Self-treatment guidelines or self-treatment plans & & $\checkmark$ & $\checkmark$ & Netherlands ${ }^{33 ; 108-111}$ \\
\hline Specific directions & & $\checkmark$ & & $U^{103}$ \\
\hline $\begin{array}{l}\text { Treatment plans (generally) or specifically for } \\
\text { urgent or emergency care }\end{array}$ & $\checkmark$ & $\checkmark$ & $\checkmark$ & Australia, ${ }^{78} \mathrm{Canada}^{58}$ New Zealand, ${ }^{102 ; 112}$ UK, ${ }^{36}$ USA ${ }^{14: 32 ; 77: 87: 90 ; 113: 114}$ \\
\hline Written crisis plan for severe asthma & $\checkmark$ & $\checkmark$ & & Australia, ${ }^{12} \mathrm{UK}^{20}$ \\
\hline \multicolumn{5}{|c|}{$\begin{array}{l}\text { Notes: } \quad+\text { Country is based on work location of author(s) listed on these publications. } \\
+十(\text { ) The word in brackets is optional e.g. authors could refer to an asthma action plan or action plan. }\end{array}$} \\
\hline
\end{tabular}


N Ring et al.

Table 3. Some extracts from the asthma plan terminology timeline.

1989

- 'Written, individualised action plan' based on peak flow readings recommended as part of a comprehensive 'six step asthma management plan'. ${ }^{21}$ Cards for children 'which provide an action plan for emergency treatment at home and in the hospital' were also suggested so children/parents could 'cope' with most symptoms and attacks without recourse to a doctor'. ${ }^{115}$

\section{0 s}

- $\quad 1$ st UK asthma guidelines defined 'self-management plans' as consisting of: 1) monitoring of symptoms, peak flow and drug usage, 2) patients taking pre-arranged action according to 3) written guidance' ${ }^{22}$

- The term 'guided self-management plan' was suggested as 'a more satisfactory title' than 'self-management plan'. ${ }^{26}$

- Global strategy for asthma management and prevention referred to an asthma management programme with 'individual medication plans for long-term management' and 'individual plans for managing exacerbations'. ${ }^{67}$ Medication plans were 'a specific plan, preferably written ... to achieve and maintain control of asthma based on use of controller and reliever medications in a stepwise approach. ${ }^{67}$ [This] included instructions on how to recognise worsening asthma and what actions to take (this part of the medication plan is often referred to as 'the action plan because it outlines how to start treatment of an exacerbation and when and how to see medical care'). ${ }^{67}$

- Cochrane systematic review reported that education in asthma self-management involving self-monitoring by peak expiratory flow or symptoms, coupled with regular medical review and a 'written action plan' improves health outcomes for adults with asthma.

\section{0 s}

- UK asthma guidelines 'proposed' 'action plan' as a 'replacement' for 'self-management plan' on the grounds of patient preferences ${ }^{23}$

- Systematic review of the components of 'written action plans for asthma. ${ }^{28}$ Defined as a 'set of instructions ... [for patients to] use in the management of deteriorating asthma,' individualised plans would inform patients about modifying medications and accessing medical care. 'Action plans' were classified e.g. 'individualised complete' according to the information they contained and the extent to which patients could alter medications. ${ }^{28}$ 'Action points' e.g. symptom levels determined when action plans should be 'activated. ${ }^{28}$

- International primary care asthma guidelines published and referred to 'individual plans for managing exacerbations' 'self-management plans' (for moderate-severe asthma), 'asthma medication plans', 'written action plan' (symptom and peak flow based outlining how to respond to an exacerbation), 'individualised treatment plans for children' and 'individualised asthma plan based on symptoms'. ${ }^{68}$

- Revised American guidelines noted 'confusion over previous guidelines' use of different terms for asthma management plans' and the need for patients to have 'instructions for managing acute and long-term asthma. ${ }^{14}$ The report states it uses 'one term written asthma action plan' but the document also refers to 'treatment plan' and 'asthma discharge plan'. ${ }^{14}$

- The 2009 GINA guidelines still refer to a variety of terms e.g. 'written self-management plan, personal asthma action plans, written selfmanagement action plan, guided self-management plan, medication plan and action plan to maintain asthma control."116 


\section{Online supplementary reference list:}

55. Donald KJ, McBurney H, Browning C. Self management beliefs: attitudes and behaviour of adults with severe life threatening asthma requiring an admission to hospital. Aust Fam Physician 2005;34:197-200.

56. Heard A, Richards I, Alpers J, Pilotto L, Smith B, Black J. Randomised controlled trial of general practice based asthma clinics. Med J Aust 1999;171:68-71.

57. Ducharme FM, Bhogal SK. The role of written action plans in childhood asthma. Curr Opin Allergy Clin Immunol 2008;8:177-88. http://dx.doi.org/10.1097/ACl.0b013e3282f7cd58.

58. Kaplan A. Inadequately controlled asthma: patients do not understand their treatment plans. Can Fam Physician 2002;48:1280-2.

59. Kaplan A. Personalised action plans: how to help your patients manage their asthma. Can Fam Physician 2002;48:1346-7.

60. Turner MO, Taylor D, Bennett R, Fitzgerald JM. A randomised trial comparing peak-expiratory flow and symptom self-management plans for patients with asthma attending a primary care clinic. Am J Respir Crit Care Med 1998;157:540-6.

61. Rasmussen L, Phanareth K, Nolte H, Backer V. Internet-based monitoring of asthma: a long term, randomised clinical study of 300 asthmatic subjects. J Allergy Clin Immunol 2005;115:1137-41. http://dx.doi.org/10.1016/ j.jaci.2005.03.030.

62. Haahtela T, Tuomisto LE, Pientinalho A, et al. A 10 year asthma programme in Finland: major change for the better. Thorax 2006;61:663-70. http://dx.doi.org/10.1136/thx.2005.055699.

63. Couturaud F, Proust A, Frachon I, et al. Education and self-management: a one year randomised trial in stable adult asthmatic patients. J Asthma 2002;39:493-500. http://dx.doi.org/10.1081/JAS-120004913.

64. Global Initiative for Asthma (GINA). A pocket guide for asthma management and prevention in children 5 years and younger. NHLBI, NIH, USA \& World Health Organisation (WHO); 2009.

65. Hargreave FE, Dolovich J, Newhouse MT. The assessment and treatment of asthma: a conference report. J Allergy Clin Immunol 1990;85:1098-111.

66. International Paediatric Asthma Consensus Group. Asthma, a follow up statement from an international paediatric asthma consensus group. Arch Dis Child 1992;67:240-8. http://dx.doi.org/10.1136/adc.67.2.240.

67. National Institutes of Health, National Heart Lung and Blood Institute. Global Initiative for Asthma. Global strategy for asthma management and prevention. NHLBI/WHO workshop report (no. 95-3659). Bethesda, USA: NIH \& NHLBI; 1995.

68. van der Molen T, Østrem A, Stallberg B, Stubbe Østergaard M, Singh RB. International primary care respiratory group (IPCRJ) guidelines: management of asthma. Prim Care Respir J 2006;15:35-47. http://dx.doi.org/10.1016/j.pcrj.2005.11.001

69. van der Meer V, van Stel H, Detmar S, Otten W, Sterk P, Sont J. Internet-based self-management offers an opportunity to achieve better asthma control in adolescents. Chest 2007;132:112-19. http://dx.doi.org/10.1378/chest.062787.

70. D'Souza WD, Crane J, Burgess C, et al. Community-based asthma care: trial of a 'credit card' asthma self-management plan. Eur Respir J 1994;7:1260-5. http://dx.doi.org/10.1183/09031936.94.07071260

71. Gillies J, Barry D, Crane J, et al. A community trial of a written self management plan for children with asthma. NZ MJ 1996;109:30-3.

72. Tan NC, Tay $\mathbf{I H}, \mathbf{N g o h}$ A, Tan M. A qualitative study of factors influencing family physicians' prescription of the written asthma action plan in primary care in Singapore. Singapore Med J 2009;50:160-4.

73. Hussein S, Partridge MR. Perceptions of asthma in South Asians and their views on educational materials and self management plans: a qualitative study. Patient Educ Couns 2002;48:189-94.

74. Dinakar C, Van Osdol TJ, Wible K. How frequent are asthma exacerbations in a pediatric primary care setting and do written asthma action plans help in their management? J Asthma 2004;41:807-12. http://dx.doi.org/ 10.1081/JAS-200038418.

75. Janson S, Becker $\mathrm{G}$. Reasons for delay in seeking treatment for acute asthma: the patient's perspective. J Asthma 1998;35:427-35.

76. Lefevre F, Piper M, Weiss K, Mark D, Clark NM, Aronson N. Do written action plans improve patient outcomes in asthma? An evidence-based analysis. J Fam Pract 2002;51:842-65.

77. National Institutes of Health, US Department of Health and Public Services. Executive summary: guidelines for the diagnosis and management of asthma. National Asthma Education Program Expert Panel Report (no. 91-3042A). Bethesda, USA: US Department of Health \& Human Services; 1991.

78. Harris GS, Shearer AG. Beliefs that support the behaviour of people with asthma: a qualitative study. J Asthma 2001;38:427-34.

79. Global Initiative for Asthma (GINA). GINA Pocket Guide for Asthma Management and Prevention: a pocket guide for physicians and nurses. Updated from the NHLBI/WHO Workshop Report (no. 02-3659). Bethesda, USA: NIH \& NHLBI; 2005.

80. Thoonen B, van Weel C. Self management in asthma care. BMJ 2000;321:1482-3. http://dx.doi.org/10.1136/bmj.321.7275.1482.

81. Buetow S, Adair V, Coster G, Hight M, Gribben B, Mitchell E. GP care for moderate to severe asthma in children: what do infrequently attending mothers disagree with and why? Fam Pract 2003;20:155-61. http://dx.doi.org/10.1093/fampra/20.2.155.

82. Osman LK. Guided self-management and patient education in asthma. British J Nurs 1996;5:785-99.

83. Rees J. Asthma control in adults. BMJ 2006;332:767-71. http://dx.doi.org/10.1136/bmj.332.7544.767.

84. Buford TA. Transfer of asthma management responsibility from parents to their school-age children. J Pediatr Nurs 2004;19:3-12. http://dx.doi.org/10.1016/j.pedn.2003.09.002.

85. Homer C, Forbes P, Horvitz L, Peterson L, Wypij D, Heinrich P. Impact of a quality improvement program on care and outcomes for children with asthma. Arch Pediatr Adolesc Med 2005;159:464-9.

86. Lieu TA, Quesenberry CP, Capra AM, Sorel ME, Martin KE, Mendoza GR. Outpatient management practices associated with reduced risk of pediatric asthma hospitalisation and emergency department visits. Pediatr 1997; 100:334-41.

87. Meng A, McConnell S. Decision making in children with asthma and their parents. J Am Acad Nurs Pract 2002;14:363-71.

88. National Institutes of Health, National Heart Lung and Blood Institute. Considerations for diagnosing and managing asthma in the elderly. NAEPP working group report (no. 96-3662). Bethesda, USA: NIH \& NHLBI; 1996.

89. Thornett AM, Newbury JW, Duszynski AJ. Should we still give our asthmatic patients written individualised management plans? Med J Aust 2002;177:459.

90. Horner SD. Catching the asthma: family care for school-aged children with asthma. J Pediatr Nurs 1998;13:356-66.

91. Haahtela T, Klaukka T, Erhola M, Lai, Laitinen LA. Asthma programme in Finland: a community problem needs community solutions. Thorax 2001;56:806-14. http://dx.doi.org/10.1136/thorax.56.10.806.

92. Buhl R, Price D. Patients' perceptions of well-being using a guided selfmanagement plan in asthma. Int J Clin Pract 2004;58:s26-s32.

93. British Thoracic Society. British guidelines on the management of asthma: 1995 review and position paper. Thorax 1997;52:s1-s20.

94. Jones A, Pill R, Adams S. Qualitative study of views of health professionals and patients on guided self management plans for asthma. BMJ 2000;321:150710. http://dx.doi.org/10.1136/bmj.321.7275.1507.

95. MacDonald P. Understanding and treating asthma in adolescents. Paediatr Nurs 2003;15:34-6.

96. Madge P, McColl J, Pearce N. Impact of a nurse-led home management 
N Ring et al.

training programme in children admitted to hospital with acute asthma: a randomised controlled study. Thorax 1997;52:223-8. http://dx.doi.org/ 10.1136/thx.52.3.223.

97. Dales RE, Kerr PE, Schweitzer I, Reesor K, Gougeon L, Dickinson G. Asthma management preceding an emergency department visit. Arch Int Med 1992;152:2041-4.

98. National Institutes of Health, World Health Organization. Global Strategy for Asthma Management and Prevention: NHLBIMHO workshop report (no. 953659). Bethesda, USA:NIH \& NHLBI; 1995.

99. Cote J, Cartier A, Robichaud P, et al. Influence on asthma morbidity of asthma education programs based on self-management plans following treatment optimization. Am J Respir Crit Care Med 1997;155:1509-14.

100. Cote J, Bowie D, Robichaud P, Parent J-G, Battisti L, Boulet L-P. Evaluation of two different educational interventions for adult patients consulting with acute asthma exacerbation. Am J Crit Care Med 2001;163:1415-19.

101. Partridge MR. Self-care plans for asthmatics. The Practitioner 1991;235:71521.

102. Fishwick D, Beasley R. Use of peak flow based self-management plans by adult asthmatic patients. Eur Respir J 1996;9:861-5. http://dx.doi.org/ 10.1183/09031936.96.09050861.

103. Brewis RAL. Patient education, self-management plans and peak flow measurement. Respir Med 1991;85:457-62.

104. Charlton I, Charlton G, Broomfield J, Mullee MA. Evaluation of peak flow and symptoms only self management plans for control of asthma in general practice. BMJ 1990;301:1355-9. http://dx.doi.org/10.1136/ bmj.301.6765.1355.

105. Foster G, Gantley M, Feder G, Griffiths C. How do clinical nurse specialists influence primary care management of asthma? A qualitative study. Prim Care Respir J 2005;14:154-60. http://dx.doi.org/10.1016/j.pcrj.2005.02.004.

106. Milnes L, Callery P. The adaptation of written self-management plans for children with asthma. JAN 2003;41:444-53.

107. Bone RC. Goals of asthma management. Chest 1996;109:1056-65. http://dx.doi.org/10.1378/chest.109.4.1056.

108. Colland VT, van Essen-Zandvliet, Lans C, Denteneer A, Westers P, Brackel HJL. Poor adherence to self-medication instructions in children with asthma and their parents. Patient Educ Couns 2004;55:416-21. http://dx.doi.org/10.1016/j.pec.2003.04.010.

109. Klein JJ, van der Palen J, Uil SM, Zielhuis GA, Seydel ER, van Herwaarden. Benefit from the inclusion of self-treatment guidelines to a self-management programme for adults with asthma. Eur Respir J 2001;17:386-94.

110. Thoonen B, Jones KP, van Rooij $H A$, et al. Self-treatment of asthma: possibilities and perspectives from the practitioner's point of view. Fam Pract 1999;16:117-22.

111. van der Palen J, Klein JJ, Rovers MM. Compliance with inhaled medication and self-treatment guidelines following a self-management programme in adult asthmatics. Eur Respir J 1997;10:652-7. http://dx.doi.org/10.1183/ 09031936.97.10030652.

112. Buetow S, Adair V, Coster G, Hight M, Gribben B, Mitchell E. GP care for moderate to severe asthma in children: what do infrequently attending mothers disagree with and why? Fam Pract 2003;20:155-61.

113. Barnes PJ. A new approach to the treatment of asthma. New Eng J Med 1989;321:1517-27

114. Mellins RB, Evans D, Asthma UK, Clark NM, Zimmerman B, Wiesemann S. Developing and communicating a long-term treatment plan for asthma. Am Fam Physician 2000;61:2419-26.

115. Warner JO, Götz M, Landau LI, et al. Management of asthma: a consensus statement. Arch Dis Child 1989;64:1065-79. http://dx.doi.org/ 10.1136/adc.64.7.1065.

116. Global Initiative for Asthma (GINA). Global Strategy for Asthma Management and Prevention. GINA; 2009 (www.ginasthma.org. accessed 2010).

117. NHS Confederation, British Medical Association. New GMS Contract 2003: investing in general practice. London: NHS Confederation \& British Medical Association; 2007. 